\title{
SISTEM PENGARSIPAN DOKUMEN GURU DAN PEGAWAI MENGGUNAKAN METODE MIXTURE MODELLING BERBASIS WEB
}

\author{
${ }^{[1]}$ Sri Lestanti, ${ }^{[2]}$ Ardina Desi Susana \\ ${ }^{[1],[2]}$ Universitas Islam Balitar
}

\begin{abstract}
Abstrak: Perkembangan teknologi meningkat sangat cepat seiring dengan perkembangan zaman. Hal itu mendorong setiap manusia terutama tata usaha sebagai salah satu penyedia informasi untuk terus menerus mengikuti perkembangan dan mengambil keputusan untuk meningkatkan, mengembangkan, dan memperbaharui setiap informasi yang disajikan untuk menunjang pelayanan yang baik. Tata Usaha merupakan bagian dari institusi yang diberi wewenang untuk menangani dokumen dan pengarsipan. Pengelolaan data kearsipan pada SMK Negeri 1 Blitar masih menggunakan cara manual, dimana petugas masih mengarsipkan dokumen diordner.

Tujuan Penelitian adalah untuk menghasilkan aplikasi pengelolaan data kearsipan di SMK Negeri 1 Blitar dari sistem manual ke dalam sistem berbasis web. Manfaat dari pembuatan aplikasi ini adalah dapat memenuhi kebutuhan pengelolaan data kearsipan pada SMK Negeri 1 Blitar secara efektif dan efisien dari sistem yang telah ada sebelumnya. Metode yang digunakan adalah observasi, wawancara, analisis, perancangan, pembangunan sistem, uji coba sistem, dan implementasi. Pembuatan aplikasi ini dibangun untuk pengelolaan dokumen guru dan pegawai. Hasil yang diharapkan dari penelitian adalah aplikasi pengelolaan data kearsipan yang dapat menghasilkan output seperti yang diharapkan dan proses pengarsipan dokumen dapat dilakukan dengan lebih baik, cepat, dan mudah.
\end{abstract}

Kata kunci :Arsip, SMK Negeri 1 Blitar, Tata Usaha

\section{a. Latar Belakang}

\section{PENDAHULUAN}

Menurut Undang-undang No. 7 tahun 1971, arsip adalah Naskahnaskah yang dibuat dan diterima oleh Lembaga-lembaga dan Badan-badan Pemerintahan dalam bentuk corak apa pun, baik dalam keadaan tunggal maupun berkelompok dalam rangka pelaksanaan kegiatan pemerataan.

Salah satu fungsi administrasi sekolah adalah pengelolaan data-data yang berhubungan dengan kepentingan di sekolah. Dalam pengelolaan data sekolah pada umumnya masih menggunakan sistem manual atau sistem pengelolaan berkas yang masih memiliki banyak kekurangan. Demikian juga yang terjadi di SMK Negeri 1 Blitar yang masih menggunakan sistem pemrosesan manual dalam pengelolaan data sekolah, yang dilakukan oleh bagian Tata Usaha. Dengan memanfaatkan perkembangan teknologi yang ada perlu dicari sistem alternatif yang dapat digunakan sebagai pengolahan data. Oleh karena itu diperlukan suatu aplikasi agar lebih mudah dan praktis. (Sudjana, 2011) 


\section{b. Rumusan Masalah}

1. Bagaimana perancangan Sistem Pengarsipan Dokumen Guru dan Pegawai menggunakan Mixture Modelling Berbasis Web secara efektif dan efisien?

2. Bagaimana menerapkan Mixture Modelling pada pengarsipan dokumen guru dan pegawai?

\section{c. Batasan Masalah}

1. Program hanya dapat diakses dilokal area SMK Negeri 1 Blitar.

2. Website pengarsipan dokumen guru dan pegawai berbasis web menggunakan PHP dan HTML.

3. Menggunakan web server Apache dan editor coding adobe dreamwever.

4. Website pengarsipan dokumen guru dan pegawai berbasis web ini membahas tentang proses pengarsipan dokumen sampai dengan menyimpannya didalam database MySQL.

5. Jumlah responden dalam penelitian ini sebanyak 20 orang, yang terdiri dari pegawai dan guru.

\section{d. Tujuan Penelitian}

1. Menyediakan sistem informasi untuk administrator dalam mengelola dokumen dan penyimpanan dokumen sesuai identitasnya ke dalam folder yang tepat menggunakan sistem informasi manajemen pengarsipan agar mudah ditemukan kembali.

2. Menerapkan Mixture Modelling sebagai metode penganalisaan data arsip dokumen guru dan pegawai yang sebelumnya tidak tertata menjadi data terkelompok sehingga memudahkan penyimpanan dan proses pencarian kembali.

\section{e. Manfaat Penelitian}

1. Dapat menyajikan informasi yang jelas mengenai data kearsipan.

2. Mampu meningkatkan efektivitas dan efisiensi kerja dalam penyediaan informasi secara cepat dan akurat.

\section{a. Tinjauan Pustaka}

\section{LANDASAN TEORI}

Dalam penelitian ini, ada beberapa kajian pustaka yang diambil oleh penulis sebagai bahan acuan pembuatan penelitian. Diantaranya adalah Bagus Dwi (2013), melakukan penelitian di SMK Negeri 1 Blitar. Penelitian ini memiliki tujuan merancang sebuah sistem digitalisasi pengarispan dokumen. Sistem yang ada dapat mempercepat pencarian dokumen karena disertakan perintah untuk pencarian otomatis. Input yang dihasilkan dari software berupa output yang dihasilkan berupa laporan data/dokumen guru dan pegawai yang telah tersimpan.

Selanjutnya, Jurnal dari Sutirman (2012), melakukan penelitian di Sekolah dengan metode Research \& Development $(R \& D)$. Penelitian ini memiliki tujuan untuk mengembangkan program aplikasi sistem kearsipan untuk sekolah dan untuk meningkatkan efektifitas dan efisiensi manajemen 
sekolah. Permasalahan yang sering muncul disekolah antara lain sulitnya menemukan kembali arsip dan dokumen yang diperlukan. Penanganan sistem kearsipan yang buruk menyebabkan sulitnya menemukan kembali surat-surat masuk yang penting, surat keluar, berkas-berkas siswa, guru maupun pegawai. Upaya yang dapat mengatasi masalah sulitnya penanganan arsip disekolah pada era teknologi komputer sekarang ini adalah dengan mengembangkan program (software) aplikasi database administrasi kearsipan berbasis komputer.

Selanjutnya Jurnal dari Daryono (2011), melakukan penelitian pengarsipan berbasis elektronik. Penelitian ini memiliki tujuan menghemat space, kapasitas simpan besar, akses informasi lebih cepat, menghemat SDM dan memperkecil kehancuran data. Informasi yang terdapat dalam arsip elektronik dapat dengan mudah untuk diubah, dihapus dan dimodifikasi sesuai dengan kebutuhan. Selain itu usia atau daya tahan fisik arsip eletronik sangat terbatas, apabila semakin sering digunakan arsip elektronik akan semakin cepat mengalami kerusakan. Dan untuk pemeliharaan fisik arsip elektronik juga memerlukan cara penyimpanan yang baik.

Dan tinjauan pustaka selanjutn 6 Jurnal dari Daniel Swanjaya (2013), melakukan penelitian tentan ${ }{ }$ Aplikasi Sistem Pengarsipan Dokumen menggunakan Metode Propotipe. Penelitian ini mempunyai manfaat arsip dan dokumen tertulis di Program Studi Teknik Informatika dapat lebih tertata dengan efektif dan efisien. Arsip dan dokumen tertulis mudah ditemukan kembali untuk mendukung proses akademik dan layanan program studi. Metode Propotipe merupakan metode pengembangan system yang digunakan dalam penelitian ini yaitu dimana model propotipe dalam mengumpulkan informasi tertentu mengenai kebutuhan informasi pengguna secara cepat.

\section{b. Kearsipan}

Kearsipan adalah suatu proses mulai dari penciptaan, penerimaan, pengumpulan, pengaturan, pengendalian, pemeliharaan dan perawatan serta penyimpanan berkas menurut sistem tertentu. Saat dibutuhkan dapat dengan cepat dan tepat ditemukan. Bila arsip-arsip tersebut tidak bernilai guna lagi, maka harus dimusnahkan.

Arsip berperan sangat penting dalam administrasi. Peranan penting arsip dalam administrasi adalah sebagai ingatan dan sumber informasi dalam rangka melakukan kegiatan perencanaan, penganalisaan, perumusan kebijaksanaan, pengambilan keputusan, pembuatan laporan, penilaian, pengendalian dan pertanggungjawaban dengan setepat-tepatnya.

\section{c. Dokumen}

Dokumen adalah surat penting atau berharga yang sifatnya tertulis atau tercetak yang berfungsi atau dapat di pakai sebagai bukti ataupun keterangan. 


\section{d. Mixture Modelling}

Mixture modelling (Mixture Modeling atau Mixture Model) adalah suatu metode yang memodel atau mengelompokkan data-data di dalam suatu dataset menjadi kelompok-kelompok data yang sebelumnya tidak terdifinisikan. Metode yang diulas adalah pengelompokan data yang memodel suatu distribusi statistik bercampur dengan distribusi statistik yang lain dalam bentuk mixture (penjumlahan berproporsi).

\section{e. HTML}

HTML adalah Bahasa pemrograman yang fleksibel di mana kita bisa meletakkan scrip dari bahasa pemrograman lain seperti JAVA,Visual Basic,C dan lain-lain. Jika HTML tersebut tidak dapat mendukung suatu perintah pemrograman tertentu.Browser tidak akan menampilkan kotak dialog"Syntax Error" jika terdapat penulisan kode yang keliru pada scrip HTML sepanjang kode-kode yang kita tuliskan merupakan kode-kode HTML tanpa penambahan kode-kode dari luar seperti java. Oleh karena itu,jika terjadi syntax error pada skrip HTML, efek yang paling jelas adalah HTML tersebut tak akan ditampilkan pada halaman jendela browser (Rio, 2005).

\section{f. $X \boldsymbol{X M P P}$}

XAMPP merupakan tool yang menyediakan paket perangkat lunak ke dalam satu buah paket.Dengan menginstall XAMPP maka tidak perlu lagi melakukan instalasi dan konfigurasi web server Apache, PHP dan MySQL secara manual. XAMPP akan menginstalasi dan mengkonfigurasikannya secara otomatis untuk anda atau auto konfigurasi

\section{g. $P H P$}

PHP merupakan bahasa pemrograman berbasis web yang memiliki kemampuan untuk memproses data dinamis. PHP dikatakan sebagai sebuah server-side embedded script language artinya sintaks-sintaks dan perintah yang kita berikan akan sepenuhnya dijalankan oleh server tetapi disertakan pada halaman HTML biasa. Aplikasi-aplikasi yang dibangun oleh PHP pada umumnya akan memberikan hasil pada web browser, tetapi prosesnya secara keseluruhan dijalankan di server.

\section{h. MySQL}

MySQL adalah sebuah implementasi dari sistem manajemen basisdata relasional (RDBMS) yang didistribusikan secara gratis. Setiap pengguna dapat secara bebas menggunakan MySQL, namun dengan batasan perangkat lunak tersebut tidak boleh dijadikan produk turunan yang bersifat komersial. MySQL sebenarnya merupakan turunan salah satu konsep utama dalam basisdata yang telah ada sebelumnya SQL (Structured Query Language). SQL adalah sebuah konsep pengoperasian basisdata, terutama untuk pemilihan atau seleksi dan pemasukan data, yang memungkinkan pengoperasian data dikerjakan dengan mudah secara otomatis. 


\section{i. Macromedia Dreamweaver}

Dreamweaver merupakan editor web yang handal. Adobe Dreamweaver tentunya dilengkapi dengan kemampuan manajemen situs, yang memudahkan kita mengelola keseluruhan elemen yang ada dalam sebuah situs. Kita juga dapat melakukan evaluasi situs dengan melakukan pengecekan broken link, kompatibilitas browser, termasuk validasi tag-tag HTML dan CSS yang tidak sesuai dengan pedoman secara otomatis serta perkiraan waktu download pada sebuah halaman web.

\section{a. Desain Sistem}

\section{Metode Penelitian}

1. Perencanaan Sistem

a) Flowchart Sistem Lama

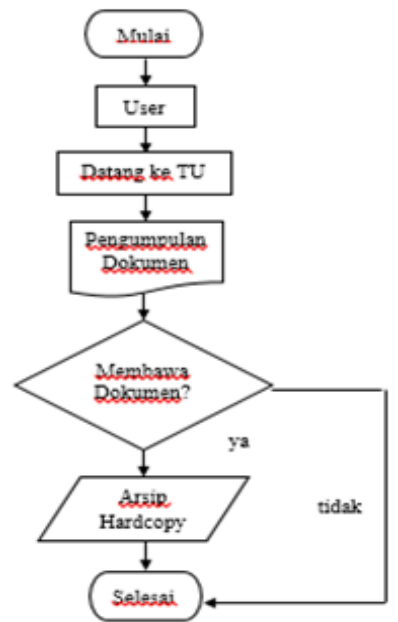

Gambar 1. Flowchart Sistem Lama

\section{b) Flowchart Sistem Baru}

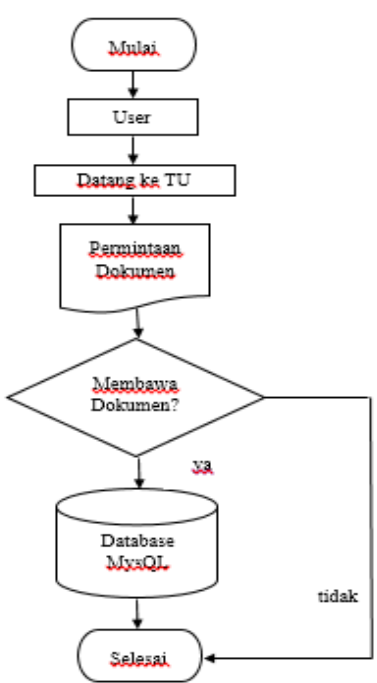

Gambar 2. Flowchart Sistem Baru 


\section{Data Flow Diagram (DFD)}

a) DFD Level 0

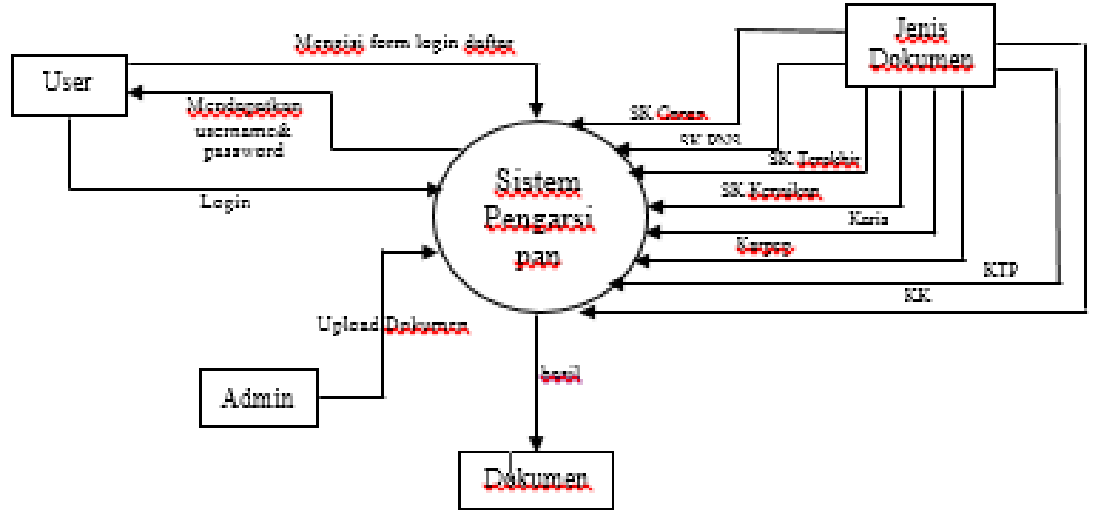

Gambar 3. DFD Level 0

b) DFD Level 1

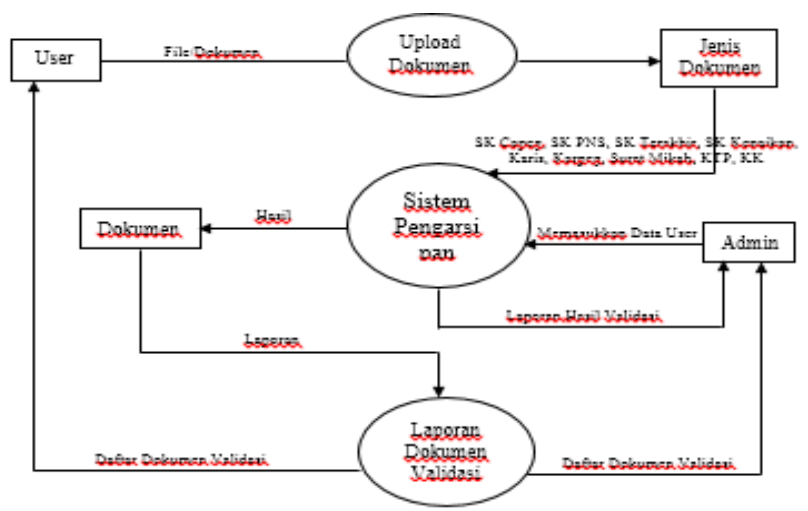

Gambar 4. DFD Level 1

\section{Perancangan Basis Data}

\section{a) Relasi Tabel}

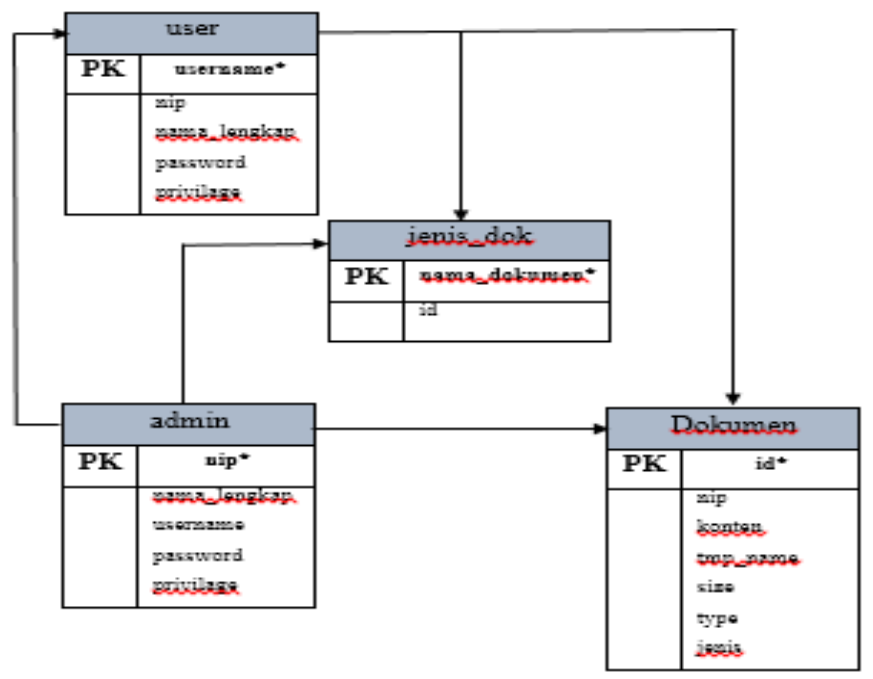

Gambar 5. Relasi Tabel 


\section{b) Entity Relationship Diagram (ERD)}

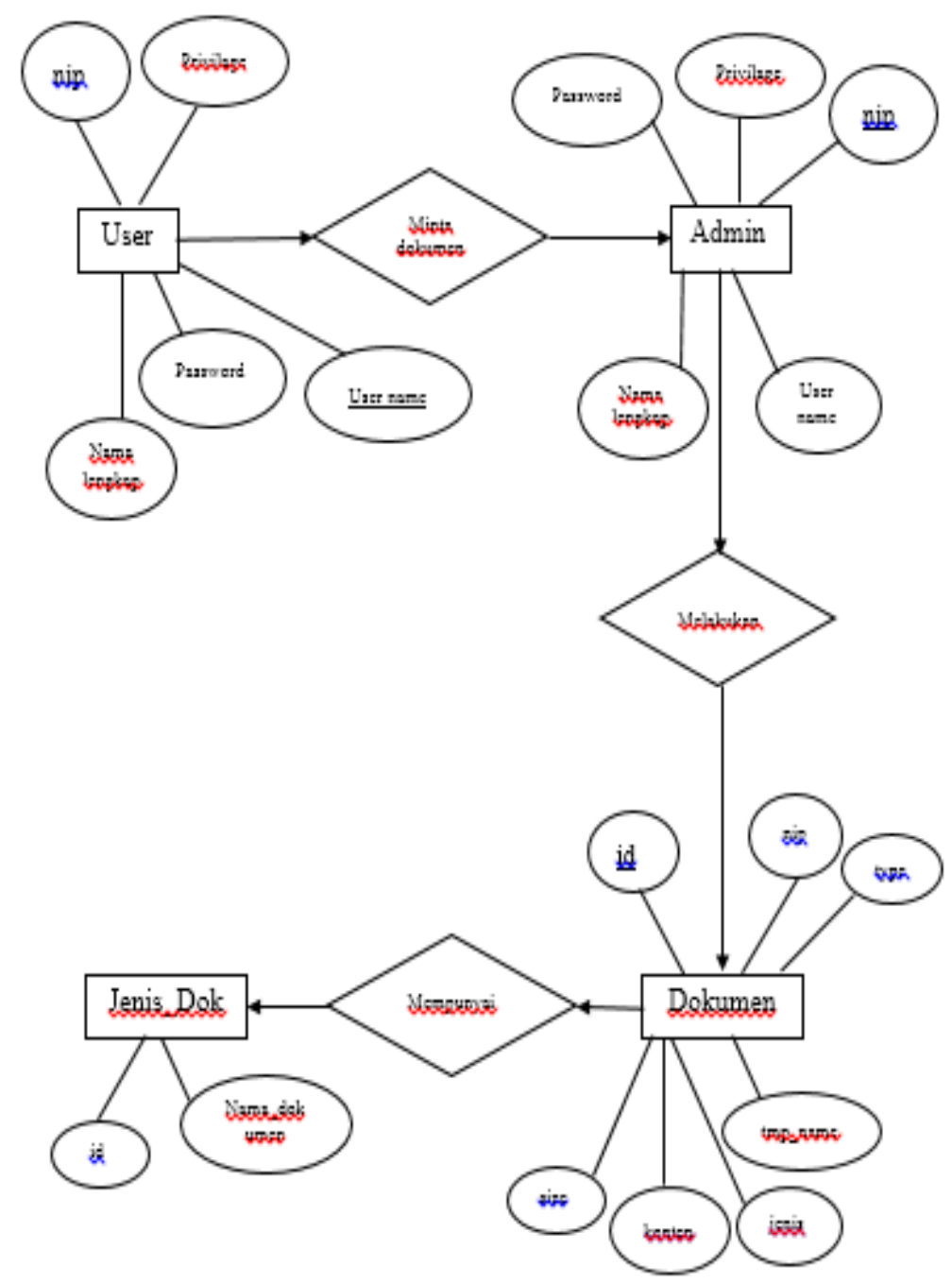

Gambar 6. ERD

\section{a. Hasil}

IV. Hasil DAN PEMBahasan

\section{Hasil Perancangan Sistem}

Perancangan sistem ini menggunakan Mixture Modelling. Dimana metode ini memberikan kemudahan dalam mengelompokkan data-data didalam suatu database menjadi kelompok-kelompok data yang sebelumnya tidak tersefinisikan. Sistem ini dirancang untuk memudahkan user dalam mencari informasi tentang dokumen apa saja yang belum dikumpulkan dibagian tata usaha khusunya dibagian pengarsipan dokumen. Dengan menggunakan sistem ini, user bisa dengan cepat mendapatkan informasi mengenai dokumen tersebut. 


\section{Implementasi Sistem}

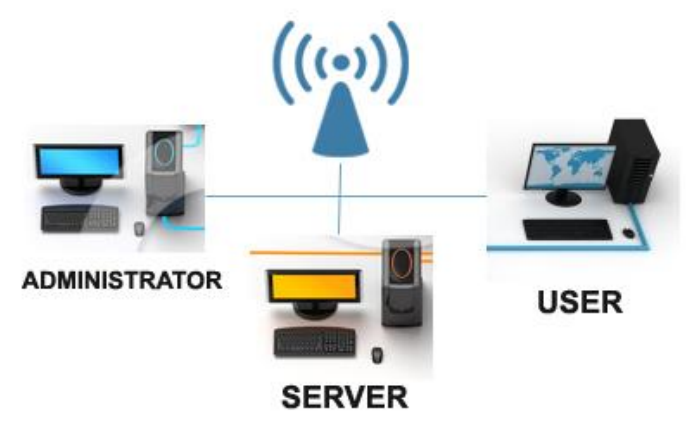

Gambar 7. Implementasi Sistem

Pada gambar 7 disajikan deskripsi dari implementasi pada sistem pengarsipan dokumen guru dan pegawai di lingkungan sekolah.

\section{b. Tampilan Web \\ 1. Halaman Utama}

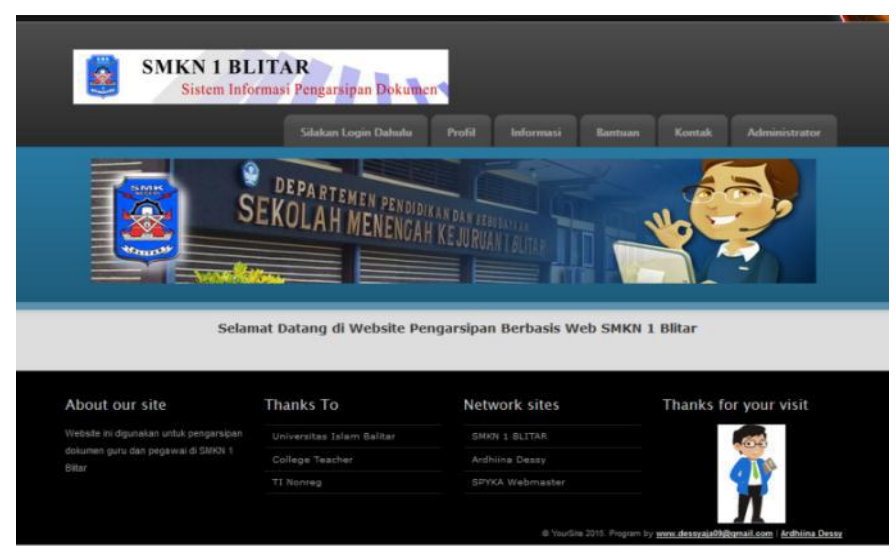

Gambar 8. Halaman Utara

Pada gambar 8 disajikan tampilan sistem pada halaman utama untuk sistem pengarsipan data guru dan pegawai.

\section{c. Pengujian Sistem}

Pengujian sistem dilakukan terhadap 20 responden yang mengisi daftar pertanyaan seperti pada bentuk questioner seperti berikut:

Tema : Perencanaan dan Implementasi Pemrograman Web untuk mengarsipkan dokumen guru dan pegawai di SMK Negeri 1 Blitar.

Respon: 20 Orang

Tujuan : Untuk mempermudah bagian TU dalam mengarsipkan dokumen guru dan pegawai.

\section{SIMPULAN}

a. SMK Negeri 1 Blitar telah memiliki aplikasi pengelolaan data kearsipan yang bisa membantu penyelesaian masalah pengarsipan dokumen.

b. Aplikasi pengelolaan data kearsipan pada SMK Negeri 1 Blitar dapat digunakan untuk mengelola dokumen. 
c. Aplikasi pengelolaan data kearsipan pada SMK Negeri 1 Blitar sangat bermanfaat dan mempercepat proses pengarsipan dokumen.

\section{DAFTAR PUSTAKA}

Andre, 2014. Fungsi Javascript. Jakarta: UIN Syarif Hidayatulloh.

Arsa,2010 Belajar Membuat Simple Add, Edit, Delete dan Search Data beserta Pagination berbasis Ajax dengan Jquery dan PHP. Surabaya : Penerbit Maulana.

Astamar, Zainul. 2004. Pemrograman Berbasis Web dan Database Development. Surabaya :Gramedia.

Daryono, 2011. Pengelolaan Arsip Berbasis Elektronik. Surabaya : Staff Universitas Negeri Surabaya.

Dwiartara, 2012. Pengertian syntax PHP. Surabaya : Penerbit Eko Susilo.

Galang Fredy, 2014. Pengertian Mysql menurut beberapa ahli. Malang: Universitas Kanjuruhan.

John S. Hartono, 2015 Penelitian Metode Penyimpanan Data. Surabaya : Gramedia.

Juristiawan Fitriansyah, Proposal Analisis Dan Perancangan Basis Data Untuk Desain Aplikasi Antar Muka Sistem Pengarsipan, Skripsi, Teknik Informatika BINA DARMA, 2013.

Lukmanul, Hakim. 2011. Trik Dahsyat Menguasai Ajax dengan JQuery. Yogyakarta : Lokomedia.

Lukmanul, Hakim. 2010. Bikin Website Super keren dengan PHP dan JQuery. Yogyakarta : Lokomedia.

Maman Suparman, 2013 Pengertian Dokumen dan Jenis Dokumen. ITS Surabaya.

Muchamad, Jeffri. 2011. Fitur-fitur Dreamweaver. Kediri : Jurnal Pembahasan.

Nana Sudjana, 2013 Pengertian dan Kelebihan MySQL, Skripsi, Teknik Informatika, UNICOM, 2013.

Novita, Simanjutak. 2011. Sejarah HTML. Yogyakarta: Penerbit Andi.

Rio, 2005. Pengertian HTML . Bogor: Universitas Bogor Indah.

Sino dan Didin, 2015. Register, Login, Logout Script (PHP). Jakarta :Erlangga.

Sriifathonah, 2015 Tata Cara Mengarsip dan Pengertiannya, Kediri : Jurnal Tentang Kearsipan Dokumen.

Sutirman, 2010. Sites Default File Penelitian. Yogyakarta : Staff Universitas Negeri Yogyakarta.

Wursanto, Widjaja, The Liang Gie, Maulana, Sedarmayanti, 1993. Pengertian Arsip, Tujuan Arsip Jakarta : Penerbit Schellenberg.

Yudi Agusta, 2015. Mixture Modelling, Yogyakarta : Lokomedia. 